\title{
TWO CASES OF PULMONARY ACTINOMYCOSIS
}

\author{
BY
}

\author{
ARTHUR G. WATKINS, M.D., F.R.C.P. \\ Physician in Children's Diseases, Cardiff Royal Infirmary and Llandough Hospital
}

Actinomycotic infection is rare in the lung and particularly so in children. Ellis (1935), who reviewed the literature and added five more cases, describes only one case in 11,500 autopsies at the Hospital for Sick Children, Great Ormond Street, London. It is therefore thought to be worth while reporting two cases seen recently in view of their clinical picture and recovery with sulphonamide therapy in heroic doses.

Case 1. On December 17, 1942, Peter D. was admitted to Llandough Hospital. He was a boy of two years and nine months who apart from measles and whooping cough had been well until three months before admission when he had an illness diagnosed as pneumonia and was kept in bed for fourteen days. After three weeks he was apparently well. A week before admission to hospital he started coughing and became feverish and off his food. Examination of the chest showed complete dullness at the left base of the lung with distant tubular breath sounds but without displacement of the cardiac impulse. X-ray showed a complete opacity of the whole of the left chest with a slight shift to the right of the mediastinum. A diagnosis of empyema was made and the chest explored. Thick greenish pus was obtained with a deposit of one-eighth of its total volume on standing for twelve hours. Mr. D. B. Foster was asked to deal with the case surgically and he proposed to do a rib resection with a closed drainage. During anaesthesia the child collapsed with a poor pulse and it was decided, fortunately in view of subsequent findings, to drain by a simple intercostal tube. The following day the Pathology Department reported 'the aspirated fluid contained numerous pus cells with gram positive cocci and a small number of gram positive branching filaments indistinguishable from streptothrix actinomycosis.' On anaerobic culture there was a pure growth of actinomyces bovis.

For the next four weeks there was considerable drainage of pus and the boy's temperature varied between normal and $100^{\circ} \mathrm{F}$. with an occasional spike to $103^{\circ}$. His general condition improved, but there was still some dullness at the left base and an $x$-ray showed a fair sized opacity with a small pneumothorax above it. The clinical signs gradually improved and the discharge lessened and for three months he remained apyrexial except for one short spell of fever due to a haemolytic streptococcal throat infection.

Five months after admission his wound broke down and started discharging pus which again contained actinomyces. A drainage tube was re-inserted under anaesthesia, but after a month this was removed and since July, 1943, there has been no discharge with no abnormal clinical signs in the chest.

When the condition was diagnosed as actinomycosis he was given Lugol's iodine 3 minims t.d.s. and this was continued throughout. In addition sulphonamide therapy was started. This was given in short spells of a week's duration of $1 \frac{1}{2}$ gm. initially and continuing with $1 \mathrm{gm}$. four-hourly by day. In all $120 \mathrm{gm}$. of sulphapyridine were given and finally, after the wound broke down, he was given $5 \mathrm{gm}$. daily of sulphadiazine continuously for thirty-four days. He thus had a total of $290 \mathrm{gm}$. over a period of six months. Throughout, a careful check was kept on his blood count, but at no time did the white cells fall below 10,000 with a maximum of 17,000 per c.mm. The polymorphonuclears remained above 50 per cent. He took both drugs without any symptomatic trouble and the urine was kept alkaline with potassium citrate and sodium bicarbonate.

On discharge he was looking well and had gained weight. There were no detectable abnormal signs in his chest; $x$-ray showed some enlargement of the left hilar gland shadow, but the lung fields were clear. He was seen three months and again six months after going home and his progress had been well maintained.

Case 2, On September 1, 1943, Jimmy M., aged eighteen months was admitted to Cardiff Royal Infirmary. He had been ill with a cough for three weeks and had collapsed on the day of admission. There had been some cough since bronchopneumonia eleven months previously. On admission the child was ill with distressed breathing and some recession of the ribs and cyanosis. His temperature was $100^{\circ} \mathrm{F}$., pulse rate 180 , and respiratory rate 58 . There were a few scattered rhonchi on both sides of the chest and an impaired percussion note at the right base. X-ray showed collapse of the right lower lobe with a pneumothorax. His condition gradually improved after placing him in an oxygen tent and five days later there was increased dullness at the right base with hyper-resonance above and tubular breath sounds. A diagnosis of a ruptured lung abscess with a pneumothorax was made. A blood count showed a leucocytosis of 13,500 per c.mm. with 62 per cent. lymphocytes and 27 per cent. polymorphonuclears.

Three weeks after admission the x-ray showed a hydropneumothorax at the right side with media- 
stinal displacement. The child's general condition was slowly improving though he still had a cough. The cough was not typical of whooping cough, though the blood film had suggested this possibility and cough plates were negative for pertussis. A Mantoux tuberculin reaction 1:1000 was negative. A week later, in view of the signs of fluid at the right base, it was decided to aspirate the chest and at the second attempt about 2 c.c. of thick pus was withdrawn. This contained numerous pus cells, and the film showed threads morphologically indistinguishable from actinomyces.

In view of the experience with the first case it was decided to treat this one on similar lines except that this time continuous chemotherapy was indicated along with alkalinization of the urine and Lugol's iodine as before. He was therefore given $5 \mathrm{gm}$. of sulphadiazine daily, and this was continued for five weeks totalling $175 \mathrm{gm}$. Owing to difficulties in obtaining this preparation treatment was changed to sulphamezathine in similar dosage for a further $70 \mathrm{gm}$. and then he was given sulphathiazole up to another $70 \mathrm{gm}$., a total of $315 \mathrm{gm}$. in all. These changes were dictated by the supplies of these drugs available. Blood counts were repeated at weekly intervals and the white cells remained high, usually around 16,000 , but ranging from 14,000 to 30,000 per c.mm. There was a variable proportion of lymphocytes and polymorphonuclears which was difficult to interpret; one week the lymphocytes would be 70 per cent. with 25 per cent. polymorphonuclears and the next the position would be reversed. This went on throughout with the lymphocytes usually predominant.

During the whole of this period the patient had remained apyrexial, but there were still scattered crepitations in his lung fields on both sides, but mainly on the right. X-ray showed complete reexpansion of the right lobe with disappearance of the fluid. Aspiration was tried again, but nothing obtained. Attempts to find the actinomyces again by stomach wash-out, post-nasal swabs and in the faeces were all unsuccessful.

Treatment stopped for a fortnight and he remained without fever, but he began to lose a little weight and his cough became worse. X-ray showed some small diffuse shadows in both lungs, the sort of film seen with a bronchopneumonia. Although the organism could not be recovered it was felt that in view of the persistence of radiological signs and the cough it was correct to continue with therapy. He was accordingly re-started with sulphathiazole at the same dosage of $5 \mathrm{gm}$. daily, and this was kept up for five weeks and two days. This gave him a total intake of various kinds of sulphonamide of $500 \mathrm{gm}$. His symptoms again improved with treatment and the $\mathrm{x}$-ray was clearer. His general condition was very much better and he had gained $8 \mathrm{lb}$. in seven months.

He was sent home four weeks after all therapy had ceased, eating well and continuing to gain weight. There were still a few crepitations in his chest from time to time and the $x$-ray picture remained unchanged. He has been seen since and remains clinically well with only a slight cough.

\section{Discussion}

In Ellis's review he found no child with actinomycosis of the lung who had recovered, but he himself recorded a child who was well $2 \frac{1}{2}$ years after the onset of his illness. It is therefore early days to be too optimistic about these two cases, although it is difficult to avoid attributing their present good health to chemotherapy.

There is an increasing literature on the treatment of actinomycosis with the sulphonamide drugs but no reference has been found of its use in pulmonary involvement in children. It is in accord with experience with these drugs that agranulocytic reactions, if they are going to take place, occur within a short time of their.initial use. Nevertheless, it is obviously important to keep a close watch on both the urine and blood. In judging the dosage in these two cases great difficulty was experienced in knowing if and when the infection had ceased. It was thought wiser therefore to continue its use and be guided by clinical signs as it was impossible to recover the organism after the first occasion. It may well be that the drugs were of no value after a certain stage, but as there was no evidence of intolerance or toxicity it seemed wise to continue them.

\section{REFERENCE}

Ellis, R. W. B. (1935). Arch. Dis. Childh., 10, 1. 